\title{
Ebooks acquisition as a shared service
}

\author{
John Tuck \\ Royal Holloway University of London
}

The growing demand for ebooks has been evident in libraries for many years. Depending on your viewpoint, moderate or extreme, ebooks are deemed to play an important role in the development or the decline of libraries. A measured forecast is outlined in Academic Libraries of the Future, a report from a project sponsored by the British Library, Jisc, the Research Information Network (RIN) and the Society of College, National and University Libraries (SCONUL 2011, p.14):

"All the scenarios assume that at some point beyond 2020 libraries will have made significant progress towards completing the digitisation of paper-based records. Practically all scientific books, papers and other records post- 1900 will have been digitised. Arts and humanities materials will have the majority of post-1950 books, papers and records digitised. Remaining paper materials required for teaching or research will normally be digitised on demand. Some special collections (e.g. extensive collections of frail manuscripts) are likely to be the exception. Libraries will develop and change to encompass the new practices and technologies."

On the other hand, in Academic library autopsy report, 2050, Sullivan (2011) considers e-books to have exerted a baleful influence:

"The academic library has died....Although the causes of death are myriad, the following autopsy report highlights a few of the key factors. 1. Book

\section{How to cite this book chapter:}

Tuck, J. 2014. Ebooks acquisition as a shared service. In: Woodward, H. (ed.) Ebooks in Education: Realising the Vision. Pp. 59-67. London: Ubiquity Press. DOI: http://dx.doi.org/10.5334/bal.g 
collections became obsolete...Most of these collections originated in physical libraries, which signed their own death warrants with deals to digitize their books."

However, the specific feedback that provided the momentum for the idea of a shared ebook acquisition service came from more localised sources: the students and librarians within the M25 Consortium ${ }^{1}$ and the Museum Librarians and Archivists Group (MLAG) ${ }^{2}$ institutions and feedback from Royal Holloway students, in surveys such as the National Student Survey and i-graduate's Student Barometer. These included:

"The library has good books on critical theory that would have been helpful to read online especially as they were not in the library", "More ebooks would make it easier to access the material" and "More ebooks please!"

As for librarians, the growing importance of ebooks was demonstrated through their participation in an ebooks survey carried out in 2011 by the M25 Consortium, Jisc Collections and MLAG, a network of archivists and librarians working in museums and galleries throughout the UK. The survey elicited 55 replies from 50 institutions and covered ebook platforms and services used by member institutions, content formats, subjects and publishers of interest, ebook business models used and possible options for consortial purchase.

Based on an assumption that the two consortia or their nominated agents would consider negotiating and centrally administering the acquisition of ebooks collections on a collaborative basis, the institutions were asked about their views on the suitability of a number of options such as: individual title purchase, individual title subscription, package purchase, package subscription, patron driven acquisition, short-term rental and access on the basis of a limited number of simultaneous users. The survey highlighted some divergent views and issues needing clarification. For example, some respondents stated a preference for a strong, robust, national approach rather than the proposed regional, consortial approach, and others identified possible conflict with existing preferred ebook platforms. In some smaller specialist institutions, respondents raised the possibility of the specialism being a barrier to a consortial approach, while others held the view that the consortial approach would be an opportunity for specialist institutions to offer more ebooks and/or achieve better pricing on specialist titles. There were also questions on how an M25 Consortium and MLAG consortia agreement would fit with other purchasing consortia agreements. The Steering Groups of the M25 Consortium and MLAG considered the feedback from the survey, and

1 The M25 Consortium of Academic Libraries is a collaborative organisation geared to improving library and information services within London and south east England. It has 57 members including small colleges, large universities, national institutions, museums and societies (http://m25lib.ac.uk)

2 http://mlablog.org 
noted that 26 of the respondents had indicated that a patron driven acquisition (PDA) approach seemed to be quite or very suitable.

This interest led to the setting up of a joint M25 and MLAG task force, not so much to deliver the service but to explore and respond to the questions raised by the survey. In timely fashion, the opportunity arose in March 2012 to submit a bid for funding under Jisc's Digital Infrastructure programme to address many of these questions and fulfil the specific aim of delivering reports, guidelines and navigation tools for consortia seeking to embark on collaborative purchasing of ebooks using PDA.

The successful bid was entitled E-BASS25 (E-Books Acquisition as a shared service in M25). The project was led by Royal Holloway University of London (RHUL) on behalf of the M25 Consortium. Specific named partners for E-BASS25 were Kingston University, the Science Museum on behalf of (MLAG), Jisc Collections and Sero Consulting Limited ${ }^{3,4}$.

\section{What is meant by PDA?}

Funding was awarded to the E-BASS25 project to identify experience and best practice from existing PDA examples and engage with stakeholders across the board in order to define their roles and expertise in this area.

A key starting point for the project was to provide a definition of PDA and investigate acquisition models that offered particular opportunities and benefits. PDA was defined as a "just in time" purchasing model which gives library users more control over which books are purchased and added to library collections. Although librarians still have a role in selecting the range of titles that are available to users, the library only pays for items that patrons use. Purchase, rental, usage, and evidence-based models were then defined and described as follows 5 .

\section{PDA purchase}

This is a straightforward PDA model which uses the available funds to purchase ebooks based on demand from customers. A selection of available titles

${ }^{3}$ All outputs of the E-BASS25 project can be found at: http://ebooksguidance.jiscinvolve.org

${ }^{4}$ Thanks are expressed to all members of the E-BASS25 project team who delivered the goals of the project to schedule and who, between them, contributed most of the content of the above report: Dominic Tate, project manager (University of Edinburgh), Anna Grigson (LSE), Kim Coles (Royal Holloway University of London), Amy Warner (Royal Holloway University of London), Carolyn Alderson (Jisc Collections), Ben Taplin (Jisc Collections), Helen Woolfries (Kingston University), Anna Vernon (British Library), Rupert Williams (Library Services, University College London - Qatar), David Kay (Sero Consulting Ltd) and Owen Stephens.

${ }^{5}$ These models are described in more details in a video EBASS25 patron-driven acquisition (PDA) e-book purchasing models (http://ebooksguidance.jiscinvolve.org/wp) 
is agreed between the library/consortium and the supplier and MARC records are loaded in the library catalogues. Users have full access to the ebooks.

\section{PDA rental}

The library consortium spreads the available funding more widely, agreeing to rent access to content up to agreed limits, before purchases are triggered. A selection of available titles is agreed between the library/consortium and the supplier and MARC records are loaded in the library catalogues. Users have full access to the ebooks.

\section{PDA usage}

This model makes use of "micropayments" to count up the actual use of the ebooks in the collection, for example a charge per page viewed. The library sets up a PDA agreement with a supplier to make a range of ebooks available to users. Once the titles have been selected, the library makes the content visible and discoverable to users. Users have full access to the ebooks. Each significant use of a book triggers a charge to the library. If the total charges payable for the book reach a given level, then the book is deemed purchased and becomes a permanent part of the library's collection. If the library decides to end the PDA agreement, access to any books which have not been purchased is withdrawn, and the library removes records for these books from the catalogue.

\section{Evidence-based selection (EBS)}

The library sets up a PDA agreement with a publisher to make a range of ebooks available to users for a defined period. Typically, libraries select one or more of the publishers' collections to be made available for a year. The library pays a fee upfront, which is typically greater than the cost of subscribing to the collection, but less than the cost of purchasing the collection. This fee will eventually be used to purchase books, but no titles are selected at this stage. The library makes the content visible and discoverable to users and users have full access to the collection for an agreed period of time (typically a year). No further charges are made.

\section{Identifying user needs}

Led by Sero Consulting, two workshops, one at the beginning and one at the end of the project, focused on user needs. The first brought together 30 librarians from 19 institutions and the second more than 45 from over 30 
institutions. The first workshop considered various acquisition models as well as the underlying drivers and motivations for each, from the perspective of libraries and suppliers. The participants were in strong support of an evidence-based PDA approach and a survey to explore further the drivers and motivations.

A survey was undertaken, predominantly of M25 Consortium members, and evoked 30 responses (more than 50\% of M25 members) The responses indicated that PDA was viewed favourably by a significant majority and seen as a user-centred approach that should be applied to more aspects of the library collection ( $80 \%$ of respondents) and should not be dismissed as a temporary supplier-driven tactic (73\%). The main motivations in offering user ebook choice were seen to be the availability of key titles (100\%), encouraging user movement to e-access $(80 \%)$ and supplementing the print collection (73\%). The most significant blockages preventing ebooks from fulfilling their potential were identified as the business models offered by publishers (87\%) and the availability of titles, especially e-textbooks (73\%). Linked to this was the view that best value in ebook acquisition was potentially to be delivered by a range of models that contribute to collection development as well as satisfying immediate demand.

From the library perspective, library-driven purchase models, informed by usage statistics over a rental period, were valued highly (90\%), as well as those involving the professional expertise of librarians and lecturers (73\%). There was a challenge to the value of access based on models not leading to ownership (67\%). As for views around the consortium approach to ebook acquisition, expectations were high for using scale to achieve the best price and making a bigger collection accessible ( $97 \%$ in both cases), more so than the reduction of the burden of procurement and administration (80\%). The most significant concerns about working in a consortium to acquire ebooks were being driven by others' subject interests that are not relevant (80\%), and domination by larger institutions (70\%).

In many ways these responses were not unexpected. After all, the respondents were professional librarians grappling with the dual aim of serving the immediate needs of their users and managing longer term collection development in the context of shrinking budgets, while the costs of e-resources continue to rise disproportionately around them.

\section{The views of publishers and aggregators}

Through a work package managed by Jisc Collections, the four models were considered with a range of aggregators and publishers, addressing issues such as minimum thresholds of investment and commitment required from consortia entering into a PDA deal with suppliers. Questions were put to the suppliers by telephone interview and the unattributed responses were 
summarised by Ben Taplin and Carolyn Alderson in a report, Publisher feedback on PDA models.

The purpose of the interviews with seven publishers and two aggregators was to discover which models they thought were feasible or realistic as a consortium purchase and learn their thoughts on the practicalities of how these models would operate. The intention was then to use the information to construct guidelines for institutions considering embarking on a PDA consortium project.

Again unsurprisingly, the evidence-based selection (EBS) model proved popular with the publishers, as it would be relatively straightforward to implement, and would guarantee some upfront payment, helping sales forecasting and planning. Seven responses favoured this model. One publisher likened it to a "paid-for trial", and one suggested that the upfront payment would be an incentive to the institution to ensure the content was used. Others mentioned its greater flexibility and sustainability and one publisher suggested that the EBS model involves a higher level of trust and cooperation between both parties and is therefore "more interesting in the long term".

The other three models were generally seen as being complicated to manage for the publisher or aggregator, entailing a considerable amount of technical work with no guarantee of payment if content is not used. This complexity was seen to increase if micropayments from a large number of institutions were involved.

General reservations were expressed about the potential for each model to offer access to content for free, and the threat posed by ebooks to print sales was still considered as a concern to publishers, especially those in the textbook market. This threat was seen to be magnified by any consortial agreement in which single copies of books are shared across several institutions. This could mean that some publishers limit the titles they make available. However, despite these concerns and reservations, the consensus among the suppliers interviewed was a willingness to explore the practicalities of each model and be flexible in order to accommodate the requirements of a consortium.

\section{Other purchasing consortia}

Engagement also took place with the Southern Universities Purchasing Consortium (SUPC), and this led to guidance on identifying the most efficient procurement routes for setting up a consortium ebooks agreement through existing framework agreements such as the Joint Consortia Book Agreement (out to tender at the time of E-BASS25). This guidance is entitled Procurement guidelines ${ }^{7}$. It makes it clear that the agreement is flexible

\footnotetext{
${ }^{6}$ Available with all the other project outputs at http://ebooksguidance.jiscinvolve.org.

7 http://ebooksguidance.jiscinvolve.org
} 
and supports a range of business models including PDA. It provides a robust mechanism for institutions wishing to purchase ebooks, but draws attention to certain factors that might inhibit the evidence-based PDA approach and collaborative purchasing by a consortium such as the M25, for instance, lack of support for procurement directly from a publisher, and eligibility to use the agreement limited to English Higher Education (HE) sector regional purchasing consortia.

\section{Developing systems guidelines}

The technical issues to be addressed in implementing a PDA agreement, and how library systems can be exploited to maximise the staff time efficiency savings that PDA offers, were explored and guidelines were produced relating to each model ${ }^{8}$. The guidelines include: the use of MARC records in a library management system; the use of MARC records in a discovery service; the use of a knowledge base and link resolver; discovery in the native interface of the publisher/aggregator rather than locally; and discovery in "next generation" library service platforms.

Through an analysis of each option, the Systems integration guidelines draw attention to key points that need to be considered and assessed at institutional and consortium level before a decision is made to embark on collaborative acquisition. For institutions, the points for consideration include the need for clarity and understanding of the discovery method to be used, how frequently records will be updated, and the level of resource required for this. There is also a need for a methodology for the removal of candidate records, the maintenance of high quality records for purchased content, and an appropriate financial tracking procedure to be in place. At consortium level, points to consider were defined as how parity might be ensured across the institutions in terms of discovery procedures, how staffing and systems might be provided for centralised payment and how monitoring of usage would be centralised to coordinate closure at an appropriate payment limit.

\section{Outcomes}

Findings from the E-BASS25 workshops and the associated survey, together with the views expressed through the publisher interviews, pointed to a strong preference for the evidence-based model. This, in turn, led the project manager, Dominic Tate, to lay down the following challenge to the M25 Consortium (Tate 2013):

${ }^{8}$ These were entitled Systems integration guidelines, by Helen Woolfries of Kingston University. Accessible at http://ebooksguidance.jiscinvolve.org 
"This brings us to the fourth model, PDA Evidence. Seemingly the most popular amongst librarians and publishers alike, this model allows patrons to access a whole range of content during the course of the agreement, with the guarantee that all the money will be spent on whole books at the end. Sounds ideal? Well, almost. Here's the rub. The library can choose which books they buy at the end of the agreement. This is great for library choice, but surely this is not actually PDA? There is an intervention between the patron and the purchase. Surely this adds an administrative burden that PDA was designed to eliminate? Perhaps this model could still achieve cost savings when scaled up to a large consortium? ... A consortium has strength to strike a deal with a publisher because its size maximises sales for the publisher and reduces their overheads of dealing with individual customers. Libraries similarly benefit through reduced overheads and similar costs so consortial purchasing is an obvious win-win. Through the size and diversity of its membership, M25 has the capability of putting together a sizeable consortium for the acquisition of ebooks and it seems obvious that the only way this could be achieved is by using the evidence-based model. Those wishing to participate would club their guaranteed spends together to achieve the highest possible discount. At the end of the term, those books every partner wants would be bought. The remaining fund could be divided up in line with the initial deposit, with each partner choosing their books. A number of publishers may also be interested in trialling this approach to see if success could be achieved in practice. Such an approach would be a departure from conventional purchasing practices and would require significant guidance from the consortium and there is always a chance it might not work, but, hey, perhaps M25 should give it a try? If we don't give it a try, we'll never know. Over to M25...”

This approach combines the features of library intervention with a guaranteed upfront payment for publishers. It cannot, therefore, be described as PDA in the purest sense. However, it does combine key elements of the PDA definition. Properly managed, it does give library users more control over which books are purchased and added to library collections and the library only pays for items that patrons use. It is in this spirit that the M25 Consortium is seeking to take up the project manager's challenge, and is undertaking discussions with Jisc Collections and publishers with a view to assessing the feasibility of a collaborative ebooks purchasing model based on the evidence-based approach and in line with the M25 Consortium strategy for $2013 / 14$ to $2015 / 16^{9}$.

In the meantime further important work on e-books has been undertaken under the Jisc Co-Design Programme. The Ebooks co-design report (Chowcat et al. 2014) set out to understand the "pain points" experienced by libraries in terms of management and user experience in dealing with ebooks in all their

${ }^{9}$ http://m25lib.ac.uk 
guises and to identify actions that might be taken at local library, consortium or national levels and in the supply chain to address them.

It is the intention that the outcomes of the Ebooks co-design report and the E-BASS25 project can be used to guide and benefit the work of the M25 Consortium in order both to address some of the "pain points" and to deliver an improved and value-for-money service experience for the ebook user.

In other words, ebooks continue to develop in exciting, innovative and disruptive ways. They present challenges and opportunities to many stakeholders: librarians, users, publishers, aggregators, teachers, etc. This is why they are of such importance within the constantly shifting digital landscape.

As for the tipping point and the future of the printed book, perhaps clues can be found in a handwritten inscription recently found in the sixth printing of a Collector's Library edition of Virginia Woolf's Mrs Dalloway, first published in this edition by CRW Publishing in 2003, and purchased in an Oxfam bookshop in Reading in December 2013:

"To Kate,

In case your kindle breaks.

Happy birthday and

Happy sabbatical,

Lots of love..."

\section{References}

Chowcat, I., Kay, D. and Stephens, O., with Devenney, A. and Stone, G. (2014) Ebooks co-design report. http://knowledgebaseplus.wordpress.com/ ebooks-co-design-project/ebooks-full-report

SCONUL (2011) Academic libraries of the future. http://www.sconul.ac.uk/ page/academic-libraries-of-the-future

Sullivan, B.T. (2011) Academic library autopsy report, 2050. The Chronicle of Higher Education, $2^{\text {nd }}$ January. http://chronicle.com.article/AcademicLibrary-Autopsy/125767

Tate, D. (2013) Reflections on the E-BASS25 project. http://ebass25.rhulo. ac.uk/2013/02/21/refections-on-the-e-bass25-project 